\section{What Increases the Risk of Dental Traumatism in Patients with Developmental Disabilities?}

Xana Carolina de Pereira e Souza', Mauro Henrique Nogueira Guimarães Abreu', Vera Lúcia Silva Resende², Lia Silva de Castilho²
'Department of Social and Preventive Dentistry, Faculty of Dentistry, Federal University of Minas Gerais State, Brazil ${ }^{2}$ Department of Restorative Dentistry, Faculty of Dentistry, Federal University of Minas Gerais State, Brazil

Correspondence: Lia Castilho, Avenida Presidente Antônio Carlos, 6627 Pampulha, 31270-010 Belo Horizonte, MG, Brazil, Tel: +55-31-3304-1307. email: liasc@odonto.ufmg.br

\begin{abstract}
This study investigated risk factors for tooth injuries in individuals from a dental clinical reference service for patients with special needs in Belo Horizonte, MG, Brazil. This is a retrospective cohort study that evaluated 493 dental charts of individuals with or without tooth injuries at their first dental appointment. The dependent variable was the time of occurrence of new dental traumatic injuries and was measured in months. Gender, age, International Code of Diseases, mother's education, mouth breathing, hyperkinesis, pacifier use, thumb sucking, psychotropic drug use, tooth injuries at the first dental examination, involuntary movements, open bite, having one or more siblings and reports of seizures were the covariates. The Cox proportional hazards regression model was used to estimate the unadjusted and adjusted hazard ratios and their respective $95 \%$ confidence intervals. The average time that individuals remained free of dental traumatism was 170.78 months (95\% Cl, 157.89-183.66) with median of 216 months. The incidence of new events was $11.88 \%$. The covariate associated with an increased risk of dental traumatism was a history of tooth injuries at the first dental appointment. The increase in dental trauma risk was 3.59 (95\% Cl, 1.94-6.65). A history of traumatic dental injury was the risk factor for the dental trauma found in this group of individuals with developmental disabilities.
\end{abstract}

Key Words: tooth injuries; tooth fractures; developmental disabilities; dental care for disabled; retrospective studies

\section{Introduction}

Evaluation of prevalence, incidence and risk factors associated with dental trauma is fundamental for the development of health strategies and organization of dental services for emergency, restorative, rehabilitation and followup care of the individuals who suffered the traumatic injury.

Among individuals with developmental disabilities, the problem takes on a more worrying proportion, since the patient does not always have a cognitive degree that allows him or her to collaborate with the necessary dental care (immobilization, endodontic treatments, complete crown, direct restorations). The solution to the problem of the traumatized tooth when the patient does not cooperate often is the exodontia of the element that suffered the injury (1-6). Dental trauma is one of the most prevalent oral health problems and causes physical, emotional, and economic consequences for the individual and his or her family (7). Depending on the frequency and impact on quality of life, it is currently considered a significant public health problem (8-10).

The prevalence of traumatic injuries in children with disabilities occurs more frequently than in children without disabilities $(2,3,11-14)$. In these patients, the upper central incisors are the most affected teeth $(1,4,15)$ and fractures involving only enamel and dentin are the most common $(5,16,17)$. The experience of dental trauma in this part of the population can be a result of intellectual disability, poor motor coordination, the presence of involuntary physical movements, pathological mouth reflexes, masticatory muscle spasticity, slower muscular response in defence of surrounding obstacles and inability to control abrupt spasmodic movements $(6,15)$. Overjet, lack of labial sealing and epilepsy crises are considered important biological factors that also promote an increase of the dental traumatic index (1-3). Other risk factors for dental trauma have been identified among children and adolescents without disabilities, such as previous experience of trauma $(18,19)$, bottle-feeding (20) and age (21).

As far as it was possible to review the literature, no longitudinal study in individuals with developmental disabilities was found. Longitudinal studies are a logical and direct way of studying the risk of occurrence of a particular disease and provide good information about the aetiology and the establishment of causal relationships (22). Dental care of traumatic injuries is complex, expensive and requires patient collaboration, which is often not achieved when the patient has severe motor and/or cognitive problems. It is hoped that, from the best knowledge of the distribution of the problem in this population, it will be possible to elaborate educational and clinical strategies to prevent its occurrence. Thus the aim of this study was to investigate risk factors for dental trauma in the deciduous and permanent dentition of patients with developmental disabilities who were treated at a reference dental health service in Brazil. 


\section{Material and Methods}

\section{Study Design and Population}

A retrospective cohort study was conducted based on information obtained from the dental records of a rehabilitation reference centre for people with developmental disabilities. The data were collected from the beginning of the operation of this dental service in January 1998 until March 2017. All patients who were receiving dental surgical restorative and maintenance treatment participated in this study. Patients who were treated only once were excluded. From a total of 628 records, 493 were included in this study.

The dependent variable was the time of occurrence of new dental traumatic injury presented in subsequent consultations of the patient initially treated by the dental service. The time (in months) when a new traumatic injury (event/failure) was diagnosed was recorded.

The following covariates were collected: history of dental trauma diagnosed at the first visit, age (in years), sex, medical diagnosis given by the International Code of Diseases, maternal education (up to 4 years and more than 4 years of formal education), involuntary movements (yes or no), hyperkinetic syndrome (yes or no), open bite (yes or no), use of psychotropic medications (yes or no), having one or more siblings (yes or no), present and past history of seizures (yes or no). The same diagnosis criterion for dental trauma was used during all clinical evaluations.

\section{Calibration Process}

The collection of patient information was done by a single, trained researcher (Cohen kappa $=1.0$ ) and a database was created in the Excel for Windows program (Microsoft, Redmond, USA). This database was reviewed by a different researcher with 19 years of experience in dentistry for patients with special needs.

\section{Statistical Analysis}

Statistical analysis involved three steps. Initially, a description of all covariates was made by calculating percentages, measures of central tendency and variability.

In a second step, the Kaplan-Meier method was used to estimate the mean time $(95 \% \mathrm{Cl})$ and the median survival time (which in this study will mean how long the subject will be free of a previous traumatic dental injury). A survival graph was drawn.

Finally, bivariate and multivariate Cox models were used to estimate the unadjusted and adjusted hazard ratio - HR $(95 \% \mathrm{Cl})$, respectively. Each covariant was included separately in the Cox model, and the unadjusted $\mathrm{HR}(95 \% \mathrm{CI})$ was estimated. Covariates with $P$ values of less than 0.25 were included in the final Cox model, where only variables that had Pvalues lower than 0.05 remained. Selection of variables in the final Cox model was done by the forward stepwise method (Wald). Graphical analysis was used to evaluate the adequacy of the variables to the assumption of proportional risks. The absence of the patient at dentist appointments for any reason (cessation of treatment, death), as well as the absence of dental trauma injury at the end of the monitoring period, were considered as censors. All statistical analysis was developed in SPSS software for Windows version 19.0 (SPSS Inc., Chicago, IL, USA).

\section{Ethics}

This study was submitted and approved by the Human Research Ethics Committee of Federal University of Minas Gerais State (protocol number ETIC 219/03).

\section{Results}

The most common diagnosis in the patients studied was spastic quadriplegic cerebral palsy $(40.07 \%)$, followed by spastic tetraplegia (5.7\%). The male gender was predominant (55\%) and the participants' ages ranged from 0 to 33 years with an average age at the first consultation of 4.1 years and a median of 3 years. The clinical and sociodemographic characteristics of patients with developmental disabilities in this study are presented in Table 1.

Table 1 Clinical and sociodemographic characteristics of developmentally deficient patients, Belo Horizonte, MG, Brazil, from January 1998 to March 2017

\begin{tabular}{ll}
\hline Variable & $\mathrm{N}(\%)$ \\
\hline Males $(\mathrm{n}=493)$ & $271(55.0 \%)$ \\
$\begin{array}{l}\text { Mother formal scholarship up } \\
\text { to } 4 \text { years }(\mathrm{n}=461)\end{array}$ & $405(87.8 \%)$ \\
Have brother/sister $(\mathrm{n}=480)$ & $300(62.5 \%)$ \\
IDC medical diagnosis $(\mathrm{n}=389)$ & \\
G82.4 & $21(5.7 \%)$ \\
G80.0 & $187(40.07 \%)$ \\
G80.1 & $12(3.1 \%)$ \\
G80.2 & $5(1.3 \%)$ \\
G80.3 & $4(1.0 \%)$ \\
Past history of seizures $(\mathrm{n}=487)$ & $276(56.7 \%)$ \\
Have seizures currently $(\mathrm{n}=483)$ & $143(29.6 \%)$ \\
Involuntary movements $(\mathrm{n}=480)$ & $116(24.2 \%)$ \\
Hyperkinesis $(\mathrm{n}=489)$ & $135(27.6 \%)$ \\
Use of psychotropic drugs $(\mathrm{n}=489)$ & $248(59.7 \%)$ \\
Dental traumatism prior to the & $53(11.4 \%)$ \\
first examination $(\mathrm{n}=480)$ & $100(40.6 \%)$ \\
Mouth breathing $(\mathrm{n}=488)$ & $238(48.8 \%)$ \\
Pacifier use $(\mathrm{n}=488)$ & $129.4 \%)$ \\
Digital sucking $(\mathrm{n}=491)$ & \\
Anterior open bite $(\mathrm{n}=246)$ & $(17.1 \%)$ \\
\hline
\end{tabular}


The prevalence of dental trauma at the first visit was $12.41 \%$ and the incidence was $11.8 \%$. The follow-up time ranged from 1 to 216 months and the mean time the subjects remained free of new dental trauma was 170.78 months (95\% Cl, 157.89-183.66), with a median of 216 months (Fig. 1).

Graphical analysis of the final model revealed that there was no violation of the proportional risk assumption. The only covariate that was significantly associated with increased risk of dental trauma was dental trauma at the first dental visit $(p<0.001)$. The presence of dental trauma at the first visit increased the risk of new trauma by 3.59 times (95\% Cl, 1.94-6.65).

Other variables that presented $P \leq 0.25$, such as the use of pacifiers, digital suction and diagnosis of dyskinetic cerebral palsy (G80.3) were not maintained in the final model. Table 2 shows the results of the multivariate Cox model analysis in the crude and adjusted model.

\section{Discussion}

The study evaluated prevalence, incidence and risk factors for dental trauma in individuals with developmental disabilities, and although these findings may not be generalized to the population, it is one of the few longitudinal studies or perhaps the only one investigating trauma in this part of the population.
This study found a prevalence of dental trauma similar to that found in previous studies among different diagnoses of individuals with developmental disabilities $(1,12)$, but lower than that found in some other studies $(2,3,6,23)$. The differences in epidemiological methods and statistical analysis performed in these studies may explain the differences between the results.

Despite the scarcity of studies investigating the incidence in children without developmental disabilities, one of the most recent literature reviews on the subject reports an incidence of $4.5 \%$ (8). In Brazil, the reported incidence $(18,20)$ was similar to that found in this study, although all studies found in the literature, within the limits of our knowledge, refer to individuals without developmental disabilities.

This study showed that the diagnosis of anterior dental trauma detected at the first dental appointment was independently associated with the risk of new traumatic injury in individuals with developmental disabilities. This finding reinforces the results presented by previous longitudinal studies that presented previous dental trauma as a predictive variable for the occurrence of a new traumatic event, but was performed in children without disabilities $(18,19)$. The clinical implication of this finding suggests the adoption of preventive methods by health professionals to identify individuals at greater risk of dental trauma and to

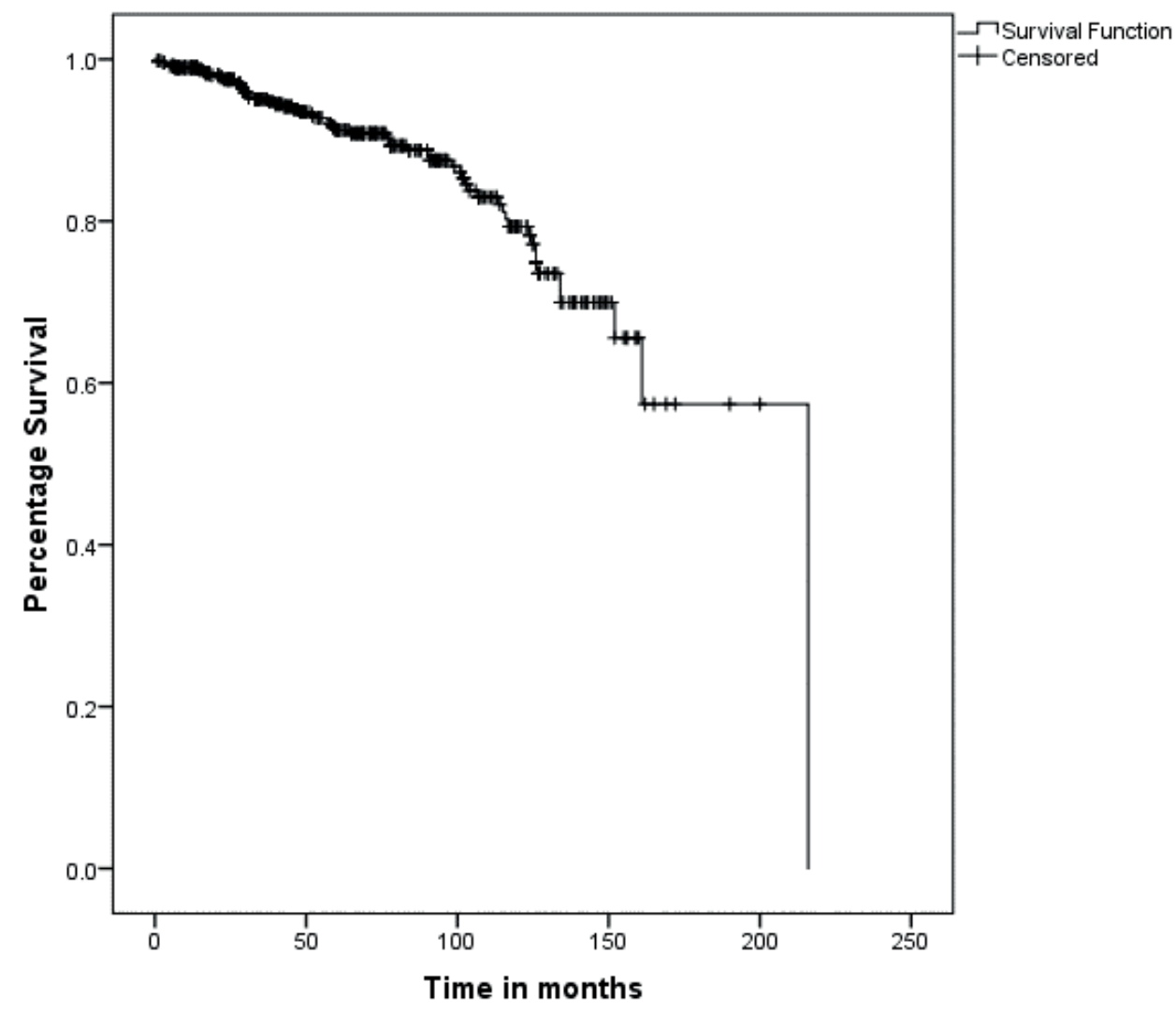

Figure 1. The average time that individuals remained free of new dental trauma was 170.78 months (95\%CI, 157.89 to 183.66$)$ with median of 216 months. 
contribute to the development of public health programmes that aim to establish preventive strategies for dental traumatism in individuals with developmental disabilities.
In addition to the findings of a recent Brazilian study investigating factors associated with dental trauma among individuals with cerebral palsy (15), gender, age,

Table 2 Risk factors for anterior dental traumatim among patients with developmental disabilities, Belo Horizonte, Brazil, 1998 to 2017

\begin{tabular}{|c|c|c|c|c|}
\hline Variable & Crude HR $(95 \%$ CI) & $\mathrm{p}$ value & Final model HR (95\% CI) & $\mathrm{p}$ value \\
\hline Age (in years) & $1.01(0.96-1.07)$ & 0.580 & & \\
\hline Male & $0.82(0.48-1.41)$ & 0.492 & & \\
\hline Female & 1 & & & \\
\hline Have brother/sister & $1.22(0.70-2.13)$ & 0.467 & & \\
\hline Does not have brother/sister & 1 & & & \\
\hline \multicolumn{5}{|l|}{ Pacifier use } \\
\hline Yes & $0.56(0.28-1.12)$ & 0.103 & & \\
\hline No & 1 & & & \\
\hline \multicolumn{5}{|l|}{ Thumb sucking } \\
\hline Yes & $1.42(0.80-2.78)$ & 0.208 & & \\
\hline No & 1 & & & \\
\hline \multicolumn{5}{|l|}{ Mother formal scholarship } \\
\hline Up to 4 years & $0.98(0.47-2.03)$ & 0.961 & & \\
\hline \multicolumn{5}{|l|}{ Diagnosis } \\
\hline G82.4 & 1 & & & \\
\hline G80.0 & $0.87(0.26-2.88)$ & 0.813 & & \\
\hline G80.1 & $2.60(0.58-11.67)$ & 0.212 & & \\
\hline G80.2 & $0.00(0.00-0.00)$ & 0.976 & & \\
\hline G80.3 & $9.27(0.92-93.86)$ & 0.059 & & \\
\hline Other & $0.98(0.28-3.41)$ & 0.970 & & \\
\hline \multicolumn{5}{|l|}{ Use of psychotropic drugs } \\
\hline Yes & $0.80(0.47-1.36)$ & 0.420 & & \\
\hline No & 1 & & & \\
\hline Have seizures currently & $1.02(0.56-1.87)$ & 0.930 & & \\
\hline Does not have seizures currently & 1 & & & \\
\hline Past history of seizures & $0.97(0.67-1.64)$ & 0.913 & & \\
\hline No past history of seizures & 1 & & & \\
\hline \multicolumn{5}{|l|}{ Involuntary movements } \\
\hline Yes & $0.83(0.45-1.53)$ & 0.565 & & \\
\hline No & 1 & & & \\
\hline \multicolumn{5}{|l|}{ Hyperkinesis } \\
\hline Yes & $0.84(0.46-1.53)$ & 0.584 & & \\
\hline No & 1 & & & \\
\hline \multicolumn{5}{|l|}{ Mouth breathing } \\
\hline Yes & $1.05(0.62-1.78)$ & 0.837 & & \\
\hline No & 1 & & & \\
\hline Dental traumatism prior to the first examination & $3.59(1.94-6.64)$ & $<0.001$ & $\begin{array}{c}3.59 \\
(1.94-6.65)\end{array}$ & $<0.001$ \\
\hline No dental traumatism prior to the first examination & 1 & & & \\
\hline \multicolumn{5}{|l|}{ Open bite } \\
\hline Yes & $0.79(0.38-1.60)$ & 0.513 & & \\
\hline No & 1 & & & \\
\hline
\end{tabular}


maternal schooling, seizures, involuntary movements, open bite, buccal breathing, use of psychotropic medication, hyperkinesis, pacifier use and digital suction were not risk factors for dental trauma in this retrospective cohort study.

The study has limitations that have already been mentioned in an earlier longitudinal study (24). In the service where these patients receive dental treatment, the team seeks to attend to them periodically, not exceeding the limit of 6 months for each patient return. However, it is not possible to accurately estimate the correct date of occurrence of dental trauma.

The purpose of dental record data from this dental service is to develop the patient's treatment plan. The diagnoses of traumatic dental injuries were made by students under the supervision of teachers as teaching and learning activity during the dental course. Although the dental records were accompanied by the same professional (an associate professor of dentistry) in this dental service during the period studied, it is not possible to have total control over secondary data obtained from outpatient and hospital records.

In addition, other variables that are considered risk factors for traumatic dental injuries were not available in these dental records and could not be evaluated. Finally, these $\approx$ data should not be generalized to the general population of patients with developmental disabilities.

The dental trauma observed in the initial dental consultation is a risk factor for new traumatic injuries in this group of individuals with developmental disabilities.

\section{Resumo}

Este estudo investigou os fatores de risco para traumatismo dentário em indivíduos da clínica odontológica de um serviço de referência para pacientes com necessidades especiais em Belo Horizonte, Brasil. Este é um estudo de coorte retrospectivo que avaliou 493 prontuários de indivíduos com ou sem traumatismo dentário em sua primeira consulta odontológica. A variável dependente foi o tempo de ocorrência de novas lesões traumáticas e foi mensurada em meses. Sexo, idade, Código Internacional de Doenças, educação materna, respiração bucal, hipercinese, uso de chupeta, suç̧ão digital, uso de medicação psicotrópica, lesões dentárias no primeiro exame odontológico, movimentação involuntária, mordida aberta, ter um ou mais irmãos e relatos de convulsões foram as covariáveis. 0 modelo de regressão de riscos proporcionais de Cox foi usado para estimar os riscos não ajustados e ajustados e seus respectivos intervalos de confiança de 95\%. 0 tempo médio que indivíduos permaneceram livres de traumatismos dentários foi de 170,78 meses (IC 95\%, 157,89-183,66) com mediana de 216 meses. A incidência de novos eventos foi de $11,88 \%$. A covariável associada a um aumento do risco de traumatismo dentário foi a história de lesões traumáticas na primeira consulta. 0 aumento do risco de traumatismo dentário foi de 3,59 (IC 95\%, 1.94-6.65). 0 histórico de lesão dentária traumática foi o fator de risco para o traumatismo encontrado neste grupo de individuos com deficiências de desenvolvimento.

\section{References}

1. Al-Batayneh $\mathrm{OL}, \mathrm{O}$ wais $\mathrm{Al}, \mathrm{Al}-\mathrm{Saydali} \mathrm{MO}$, Waldman HB. Traumatic dental injuries in children with special health care Needs. Dental Traumatol 2017;33:269-275.

2. Jalihal $S$, Nagarajappa $R$, Sharda A, Asawa K,Tak M. Assessment of dental trauma among cerebral palsy individuals in Udaipur city. Dent Traumatol
2012;28:448-451.

3. Miamoto $C B$, Ramos-Jorge ML, Ferreira MC, Oliveira M, Vieira-Andrade RG, Marques LS. Dental trauma in individuals with severe cerebral palsy: prevalence and associated factors. Braz Oral Res 2011;25:319-323.

4. Ferreira MCD, Guaré RO, Prokopowitsch I, Santos MTBR. Prevalence of dental trauma in individuals with special needs. Dent Traumatol 2011;27:113-116.

5. Holan G, Peretz B, Efrat J, Shapira Y. Traumatic injuries to the teeth in young individuals with cerebral palsy. Dent Traumatol 2005;21:65-69.

6. Santos MTBR, Souza CBC. Traumatic dental injuries in individuals with cerebral palsy. Dent Traumatol 2009; 25:290-294.

7. Aldrigui JM, Abanto J, Carvalho TS, Mendes FM, Wanderley MT, Bönecker

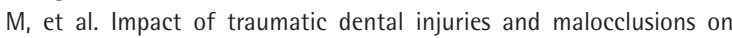
quality of life of Young children. Health Qual Life Outcomes 2011;9:7884.

8. Lam R. Epidemiology and outcomes of traumatic dental injuries: a review of the literature. Aust Dent J 2016;61:4-20.

9. Antunes LAA, Leão AT, Maia LC. The impact of dental trauma on quality of life of children and adolescents: a critical review and measurement instruments. Ciência \& Saúde Coletiva, 2012;17:3417-3424.

10. Glendor U. Epidemiology of traumatic dental injuries - a 12 year review of the literature. Dent Traumatol 2008;24:603-611.

11. Habibe RC, Ortega AO, Guare RO, Diniz MB, Santos MT. Risk factors for anterior traumatic dental injury in children and adolescents with autism spectrum disorders: a case-control study. Eur Arch Paediatr Dent 2016;17:75-80

12. Murthy AK, Chandrakala B, Pramila M, Ranganath S. Dental trauma in children with disabilities in India: a comparative study. Eur Arch Paediatr Dent 2013;14:221-225.

13. Nunn JH, Murray JJ. The dental health of handicapped children in Newcastle and Northumberland. Br Dent J. 1987;162:9-14.

14. Ohito FA, Opinya GN, Wangombe J. Traumatic dental injuries in normal and handicapped children in Nairobi, Kenya. E Afr Med J. 1992; 69:680682.

15. Cardoso AMR, Silva CRD, Gomes LN, Gomes MNC, Padilha WWN, Cavalcanti AL. Dental Trauma in Brazilian children and adolescents with cerebral palsy. Dent Traumatol 2015;31:471-476.

16. Al-Hammad N. Tooth wear, enamel hypoplasia and traumatic dental injuries among cerebral palsy children of Riyadh city. King Saud Univ J Dent Sci $2011 ; 2: 1-5$.

17. Dubey A, Ghafoor PA, Rafeeq M. Assessment of traumatic dental injuries in patients with cerebral palsy. J Indian Soc Pedod Prev Dent 2015;33:2527.

18. Ramos-Jorge ML, Peres MA, Traebert J, Ghisi CZ, Paiva SM, Pordeus IA. Incidence of dental trauma among adolescents: a prospective cohort study. Dent Traumatol 2008;24:159-163.

19. Goettems ML, Brancher LC, Costa CT, Bonow MLM, Romano AR. Does dental trauma in the primary dentition increases the likelihood of trauma in the permanent dentition? A longitudinal study. Clin Oral Invest 2017;21:2415-2420.

20. Feldens CA, Kramer PF, Feldens EG, Pacheco LM, Vitolo MR. Socioeconomic, behavioral, and anthropometric risk factors for traumatic dental injuries in childhood: a cohort study. Int J Paediatr Dent 2014; 24:234-243.

21. Oldin A, Lundgren J, Nilsson M, Norén JG, Robertson A. Traumatic dental injuries among children aged $0-17$ years in the BITA study - A longitudinal Swedish multicenter study. Dent Traumatol 2015; 31:9-17.

22. Luiz RR, Costa AJL, Nadanovski, P. Epidemiologia \& Bioestatística em Odontologia. Rio de Janeiro: Atheneu; 2008. p.227-30.

23. Abanto J, Ortega AO, Raggio DP, Bönecker M, Mendes FM, Ciamponi AL. Impact of oral diseases and disorders on oral-health-related quality of life of children with cerebral palsy. Spec Care Dentist 2014;34:56-63.

24. Braúna APSV, Abreu MHNG, Resende VLS, Castilho LS. Risk factors for dental caries in children with developmental disabilities. Braz Oral Res 2016; 30:e79. 